\title{
Prevalence of nutritional problems in the world
}

\section{By D. S. Miller, Queen Elizabeth College, London W8}

It would seem reasonable to direct most nutritional research towards those problems that most afflict mankind, but in the present state of knowledge it is difficult to ascertain which these are. The first part of this paper will outline some of the difficulties but subsequently a rank order will be given which no doubt will be controversial. Thus the subject matter of this paper has revealed perhaps the most important area of research, namely the establishment of criteria for malnutrition which would enable workers to ascertain its magnitude. The research would show the numbers of people who are malnourished and would indicate their distribution by age, sex, geographical area and social class. It would not, however, indicate the effect of malnutrition on the quality of life. That malnutrition causes human misery seems beyond question, but to compare, for example, that due to obesity and dental caries on the one hand, and xerophthalmia and goitre on the other, requires value judgements that are difficult to make. It could be argued that the malnutrition of affluence is self-inflicted whereas that of the developing world is due to poverty and ignorance. Nevertheless, both are extremely costly in human and in economic terms and a more objective approach may be by considering the costs to the community.

\section{Criteria for malnutrition}

There are essentially two approaches to a definition of malnutrition which allow numerical analysis: clinical and dietary. If one takes clinical survey information to establish prevalence rates for a population, one is relying heavily on clinical judgement. It is well known that some workers see deficiency symptoms which others overlook, and there is much argument about the subtle distinction between clinical and subclinical signs. It is true that the better surveys include anthropometric and biochemical measurements which are more objective, but the problem is merely transferred to evaluating them. For example, the diagnosis of anaemia from a haemoglobin determination raises the question not only of what is the normal range but what are the risks and even benefits of low values (Elwood, 1970). Similarly, serum folate levels show a wide range in an apparently healthy population and using the criteria of WHO (1972) many people in Britain would be counted as deficient. Simple measurements of height, weight, and skinfold thickness are by far the most cost objective methods for identifying both under and over nutrition, but sadly they are also the most neglected. We need to know more about how they are influenced by genetics and climate: nevertheless, the heights and weights of children of a given age in the Far East are rising spectacularly despite the popular belief that the population there is genetically small. However, Asian children in the UK are small for age by Harvard standards but almost half $0029-6651 / 79 / 3823-2403$ Sor. 00 (C) 1979 The Nutrition Society 
would be rated obese by skinfold thickness. Mortality and morbidity information is also important but is notoriously unreliable in the undernourished countries: thus our statistics for coronary heart disease are probably much better than those for beriberi.

Dietary evidence for malnutrition should be more objective than clinical evidence. If physiological needs are not met by the diet, malnutrition is established. The problem here, is the definition of physiological need. Since the turn of the century, committee after committee has grappled with this problem and most, if not all, have concluded in terms of recommended dietary allowances for groups of people, rather than as minimum physiological requirements for individuals. The distinction is important. The former are only of value in prescribing diets, whereas the latter are essential for counting individuals who are malnourished. For example, the mean energy intake of a population may well equal the mean dietary allowance and yet contain many under- and overnourished individuals simply because the distribution of food amongst the population does not meet individual physiological needs. In fact most dietary allowances of energy are based indirectly on mean energy intakes in the western world where the prevalence of obesity is high and even undernutrition is not unknown amongst the poor. To assess the number of malnourished individuals in a population it is necessary to have cut-off points above and below which nutritional status is impaired. Then one would have a yardstick to interpret dietary survey results. This realization has recently occurred to a number of international agencies who have abandoned their own carefully argued recommended dietary allowances for new critical limits which seem to have been chosen arbitrarily. For example, the low cut-off point (minimum physiological requirement?) for energy has been taken as $20 \%$ above basal
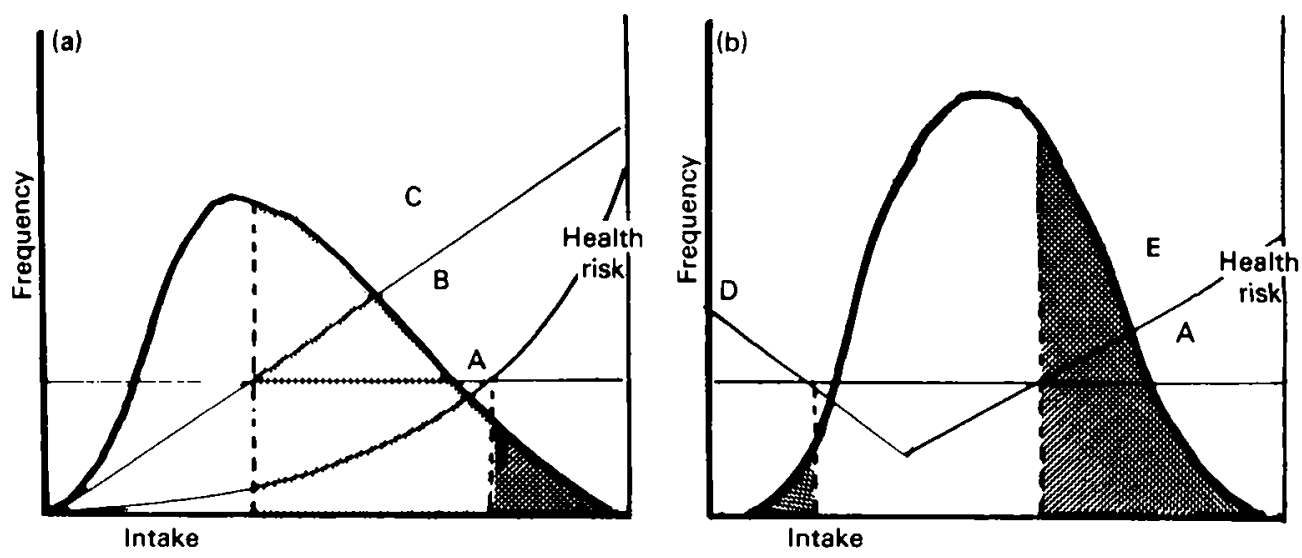

Fig. I. Two possible distributions of the intake of nutrients within a population together with a number of possible relationships between intake and risk to health for sugar (a) and other nutrients (b). The acceptable risk to health is shown by line A. B is a curvilinear risk relationship which indicates a much smaller population at risk than $\mathrm{C}$ which is a linear risk relationship. The line $\mathrm{DE}$ shows two linear risk relationships, one directly and one inversely proportional to intake: hence there are two groups at risk, those in the population consuming too little and those consuming too much of the nutrient. 
metabolic rate (I-2 BMR). Evidence for these critical limits needs to be carefully examined: in most cases there should be a relationship between dietary intake and risk to health and the cut-off points should depend upon criteria for acceptable risk. A simple example is illustrated in Figure 1a, which poses the question: how much sugar is too much? The distribution of intakes is known to be skewed, but the prevalence of either dental caries, diabetes, coronary heart disease or obesity in relation to intake is not known. The position is more complex for most nutrients, because risk does not only rise with increasing intakes, but also when they decrease: this is illustrated in its simplest form in Figure $\mathbf{I b}$, where it is assumed that intakes are not skewed and risk is proportional to intake, both directly and inversely from a fixed point of minimum risk.

\section{Criteria for food requirements}

Given the range of acceptable intakes, it is then necessary to establish the distribution of food within the population. Unfortunately there are insufficient dietary surveys for this purpose, and national food balance sheet information yield 'meaningless means' (Miller, 1969). The international agencies (FAO, 1977) base their estimates of food distribution on socio-economic information. It is claimed that the distribution of food within the population can be ascertained from income distribution by assuming a relationship between intake and income, based on energy-income elasticity. There are a number of dubious assumptions in their calculations; firstly that all individuals use money wisely when purchasing food, and secondly that intakes have a beta-distribution between an arbitrary minimum and an arbitrary maximum value. One cannot help but feel that they could have drawn the distribution curve better by freehand and avoided the mathematical complications. Nevertheless, if the numbers game must be played, they make best use of available results. At least they have established the need for cut-off points in assessing the extent of malnutrition, and such information is urgently required for food and nutrition planning, the allocation of aid to the needy, and even for propping up governments.

It may surprise some that figures for energy requirements are not known with certainty. Six years ago four workers in the field (Durnin et al. 1973) asserted that man's need for food was not known and this has not been challenged since. The fact is that man has a remarkable ability to adapt to changes in energy intake. In our own population there are individuals of the same age, sex and occupation who customarily eat twice that of others: the question is which, if any, are malnourished. Experimental work on both over and under feeding (Miller, 1978) shows that energy expenditure changes to equal intake and energy balance can be achieved at various levels and at various weights. We have identified individuals who maintain weight and apparent good health on $6300 \mathrm{~kJ} / \mathrm{d}(1500 \mathrm{kcal} / \mathrm{d})(\mathrm{Miller}$ \& Parsonage, 1975), and there are some infants that eat more than some of our students (Morgan et al. 1976).

As mentioned previously, the international agencies (FAO, 1977) have taken I.2 BMR as a minimum intake. They arrive at that figure by saying that the 
maintenance allowance is $\mathrm{I} \cdot 5$ BMR: this is equivalent to $107 \mathrm{~W}^{0.75}$ used in comparative nutrition. However, they recognize that BMR shows an individual variation and that some individuals may have a $\mathrm{BMR}$ as low as $20 \%$ less than normal: hence $0.8 \times 1 \cdot 5 \mathrm{BMR}=\mathrm{I} \cdot 2 \mathrm{BMR}$. No allowance for the energy cost of activity is made. But what they fail to recognize is that low BMR values are a symptom of undernutrition. Also the calculated values for BMR are based on height and weight which can also be low as a result of undernutrition. Thus their adopted minimum energy requirement is biased by the undernutrition they are trying to estimate. An alternative approach is to assume that energy requirements have the same distribution as food intakes and make risk estimates: this has led Lörstad (1974) to conclude, after tedious mathematical computations, that if an individual's intake is equal to the mean requirement then the probability of his being undernourished is 0.5 , and hence with eighty such individuals forty should be counted as undernourished. What he doesn't point out is that by the same argument forty would be overnourished and hence the prevalence rate for malnutrition would be $100 \%$. The fallacy is that an individual's requirement is not a single value but falls within a range. Individuals adapt to their food intakes and what is critical is whether such adaptations carry a risk or not.

Within our own population there are apparently healthy individuals who customarily consume less than the FAO critical limit of I 2 BMR, and these would be counted as malnourished; numerically they are about $3 \%$. Durnin (1979) has collected together results where whole populations would fall into this category (see Table I). These people may be characterized as being small and with little body fat, but nevertheless maintaining energy balance. We know little about their resistance to disease, although they are better adapted to the hazards of their own environment than us, and they seem able to work energetically when required. Their frugal diet is not because of food shortage but rather because of its monotony and bulk. One suspects that increasing food intake would lead to changes in body size, increased weight in the current generation, increased height in the next. In deciding whether to count them as malnourished one must be careful in not having double standards, one for us and one for them.

Table 1. Communities living on low food intakes*

\begin{tabular}{clcc} 
Sex & $\begin{array}{l}\text { Location of } \\
\text { survey }\end{array}$ & \multicolumn{2}{c}{$\begin{array}{c}\text { Energy intake } \\
\text { kJ/d (kcal/d) }\end{array}$} \\
Male & New Guinea & 8100 & $(1940)$ \\
& Ethiopia & 7900 & $(1890)$ \\
Female & Jamaica & 7250 & $(1730)$ \\
& USA & 7400 & $(1770)$ \\
& India & 6050 & $(1450)$ \\
& Jamaica & 6000 & $(1440)$ \\
& New Guinea & 6000 & $(1420)$ \\
& Ethiopia & 5600 & $(1340)$ \\
& USA & 5550 & $(1330)$ \\
& Puerto Rico & 5100 & $(1240)$ \\
& & &
\end{tabular}


Table 2. Possible nutritional standards for human adults

(Results in this Table are not well established)

Deficiency disease

Marasmus

Essential fatty acid deficiency

Constipation

Wasting

Anaemia

Cramps

Goitre

Dental caries

Xerophthalmia

Rickets

Scurvy

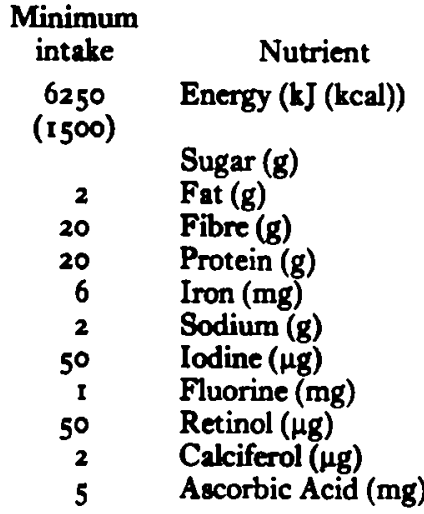

Maximum
intake
12550
$(3000)$
50
80
100
100
100
10
1000
20
10000
250
500

Chronic toxicity

Obesity

Dental caries

Heart disease

Malabsorbtion

Gout

Siderosis

Stroke

Thyrotoxicosis

Fluorosis

Hypervitaminosis

Hypercalcaemia

Renal stones

\section{Possible new nutritional standards}

It is to be hoped that future committees on nutrient requirements will provide maximum levels of intake as cut-off points which have been assessed objectively. A possible example is given in Table 2 for adult man. The only figures that are even reasonably well established are those for minimum protein and ascorbic acid requirements, and they are so low as to be unacceptable to committees so far, who have increased them by various factors for safety, largely because they have been confused between requirements and allowances. For example, the WHO (1973) figure for protein is multiplied by $1 \cdot 3$ twice to increase the value by $70 \%$. Similarly our own DHSS (1969) figure is increased to allow for individual variation: it was assumed that protein requirements follow a normal distribution and hence an addition of two standard deviations (SD) was added to the mean requirement to cover $97.5 \%$ of the population. This is another example of mystifying by mathematics: why choose $2 \mathrm{SD}$ and not $3 \mathrm{SD}$ or even $2.5 \mathrm{SD}$. It is even doubtful if requirements follow a normal distribution since there is no evidence that some odd individuals require no protein and others an infinite amount. But it really is possible to say that people who eat less than $20 \mathrm{~g} / \mathrm{d}$ should be counted as malnourished, and even if one takes the artificially increased figures it is almost impossible to attribute a simple protein deficiency to anyone in the world unless they have concomitant energy deficiency.

The appearance of sugar, fat and fibre in a Table for nutritional standards is novel, but evidence is accumulating that they ought to be included. In assessing nutritional problems in the world many obsessed with deficiency diseases omit those of affluence. Some of these have multifactorial causes but dietary influences are considerable; one has the problem of whether to count for example coronary heart disease as malnutrition. Dental caries is primarily related to sugar, fibre and fluoride intakes and should be included. An ample food supply is a necessary 
condition for the development of obesity even if it is considered to be primarily genetic in origin. Certainly it carries a high mortality risk and should be considered as a form of malnutrition.

The toxicity of mineral nutrients e.g. iron, iodine, is well established and a safe range of intakes should be easy to ascertain. Very high intakes of sodium are said to lead to the Japanese disease of affluence, stroke, and an upper limit should be stated. The toxic level of some vitamins is known, e.g. for retinol, and some believe that Linus Pauling doses of ascorbic acid are not without hazard. The establishment of safe ranges of intake above and below which there are unacceptable risks for health also has the advantage that the individual will be left with a considerable freedom of choice. Nutritionists are really not in the recommending business and have lost much credibility for trying to describe ideal diets: we should leave that to the gastronomist.

\section{Prevalence rates}

Table 3 provides a set of estimates for the extent of the major causes of malnutrition in the world. The figures are of course almost certainly wrong, but they are one set of guestimates in the numbers game. Others exist: Boyd Orr (1950) said that 'a lifetime of malnutrition and actual hunger is the lot of two-thirds of mankind' and he was not counting the diseases of affluence. It is noteworthy, however, that some of the deficiency diseases of that time have been greatly reduced due to specific measures for their eradication. This applies for example to pellagra, beriberi, rickets and scurvy which are not included in the Table because available evidence suggests low prevalence rates. However, according to DeMaeyer (personal communication) riboflavin deficiency is probably the most widespread deficiency disease in the world, but results are not available because its effects are not sufficiently debilitating.

The results for the undernourished have been taken directly from the estimates of FAO (1975) with all their limitations: they are almost certainly an overestimate. Clinical surveys of children suggest a rate of $19 \%$ with only $2.3 \%$ severe (Bengoa

\section{Table 3. Probable prevalence and extent of malnutrition in the world}

(The values given in this Table are only estimates)

\begin{tabular}{|c|c|c|c|c|c|}
\hline & \multicolumn{2}{|c|}{ Developed regions } & \multicolumn{2}{|c|}{ Developing regions } & \multirow[b]{2}{*}{$\begin{array}{c}\text { Total } \\
\text { (Millions) }\end{array}$} \\
\hline & $\begin{array}{c}\text { Prevalence } \\
(\%)\end{array}$ & $\begin{array}{l}\text { People } \\
\text { affected } \\
\text { (Millions) }\end{array}$ & $\begin{array}{c}\text { Prevalence } \\
(\%)\end{array}$ & $\begin{array}{l}\text { People } \\
\text { affected } \\
\text { (Millions) }\end{array}$ & \\
\hline Dental caries & 99 & 1060 & 10 & 175 & 1235 \\
\hline Anaemia (iron \& folate) & 5 & 54 & 30 & 525 & 579 \\
\hline Undernourished & 3 & 28 & 25 & 434 & 462 \\
\hline Heart disease & 30 & 321 & 2 & 35 & $35^{6}$ \\
\hline Obesity & 25 & 267 & 3 & 52 & 319 \\
\hline Goitre & I & II & 10 & 175 & 186 \\
\hline Xerophthalmia & 0 & 0 & $\mathbf{I}$ & 18 & 18 \\
\hline Blindness & 0 & 0 & 0.1 & 2 & 2 \\
\hline
\end{tabular}


\& Donoso, 1974). The prevalence of vitamin A deficiency has been estimated from a series of papers which show that the prevalence of xerophthalmia affects from 0.2 to $8 \%$ of children. In the Far East alone 100000 children go blind each year (FAO, 1975), i.e. $0.01 \%$ of the population, giving a total prevalence of about $0.5 \%$. The figure of $0.1 \%$ for blindness given in Table 3 is a guestimate for the developing regions as a whole, and that for xerophthalmia has been taken as ten times this. It is probably an underestimate in view of the fact that blindness from all causes is about $1 \%$ (WHO, 1978). The prevalence of anaemia in the developing regions is based on the results of Sood et al. (1968), which is supported by Layrisse et al. (1976) who estimated the prevalence rate in developing countries to be $20-40 \%$ in males but higher in women. These authors have also estimated the prevalence of anaemia in the west as $10-30 \%$ in women and rare in men, from which a modest guestimate of $5 \%$ in the whole population has been derived. The figure for goitre in Table 3 is based on the WHO monograph (Kelly \& Snedden, 1960) which reports two hundred million people affected. More recent results indicate a prevalence of $8 \%$ in Latin America (Schaefer, 1974) despite iodization programmes, and even $7 \%$ in $10-15$ year old children in the USA, and more surprisingly $20 \%$ in $20-30$ year old people in Switzerland where iodized salt has been available for 50 years (Matovinovic et al. 1974).

Dental caries affect virtually everyone who have adopted a western diet, but is not completely absent amongst even primitive people: Stones (1957) gives its prevalence amongst Eskimos as $1 \%$ and bushmen as $21 \%$. The Asian rate is about 10\% and this is the value used in Table 3 . The results for obesity are based on a few isolated surveys which used different standards for its assessment. Nevertheless since almost half the western population is more than $10 \%$ overweight, and this carries a mortality risk as great as smoking 20 cigarettes a day, the adopted guestimate is almost certainly an underestimate. The value for the prevalence of obesity in developing regions is a straight guess, but the disease is increasing in the urban areas. Approximately one-third of all deaths in developed regions are due to heart disease, but it can be argued that since its aetiology is multifactorial one should not attribute all these deaths to dietary causes. On the other hand many of those that die of other diseases were at risk from heart disease, and certainly post-mortems of all ages from all causes indicate that atheroma develops throughout life for those eating a western diet. In view of this, $30 \%$ is probably an underestimate. For countries in Asia and Africa the prevalence is very low: for example, of 40000 Bantu at the Johannesburg hospital there were only 30 cases (Schrire, 1971), and the value given in Table 3 is probably an overestimate.

\section{Nutrition and the quality of life}

The results in Table 3 are of course not additive, since some individuals may be at risk from two or more conditions. However, even allowing for large errors in the values, it is clear that malnutrition is a major public health problem, and that the diseases of affluence are at least as important 28 those due to deficiencies in the poorer parts of the world, although the latter have more emotive appeal. Certainly 
expectation of life in the west is much higher than in the poorer countries, but this is largely due to child mortality. Infant mortality alone in the developing regions of the world is currently about $10 \%$ whereas in the west it is nearer $1 \%$ (Shapiro, 1976). The chances of a child reaching adulthood in many countries is no better than evens. How far this is due to malnutrition or to poor hygiene is not certain. But how can one compare the misery of a mother who has lost a child in a culture where such things are commonplace, with that of a woman who is unmarriageable due to obesity in a culture where sexual attraction is a symbol of happiness? Similarly it can be argued that it is less of a disaster for a child to die of malnutrition than for the bread-winner to drop dead from a heart attack. Certainly a child with toothache suffers more than one with angular stomatitis. Nevertheless it is clear in all of these examples that nutritional problems are highly relevant to the human condition. It is also clear that our understanding of the problems is abysmal: we are not even sure how many people are affected.

Nutrition research in Britain is probably best directed at our own diseases of affluence. We are no longer a great colonial power and we should do something to put our own house in order. Also research on our own problems may prevent them occurring in the developing countries. Nevertheless we do have some responsibility towards the less fortunate countries and we have skills that they do not have. It is fair that some of our overseas aid to which we are committed is used for this purpose. But it is important that we should send people who are prepared to work in the bush rather than from luxury hotels, for much of the malnutrition overseas is due to poverty and ignorance and their problems are socio-economic rather than academic. One can point to some developing countries with palatial research laboratories surrounded by a sea of malnutrition: the work is often directed by personnel trained in the west and who are still working on western problems. One wonders if, for example, they can afford the luxury of studying the mode of action of retinol in the rat when the problems of distribution of the vitamin within their own populations are so great that there are still two million cases of blindness in the world: the latter is also a scientific problem which deserves the attention of the brightest intellects.

For our own malnutrition, the amount of money spent bears no relationship to the size of the problem. In some curious way, we accept dental caries and obesity as though they are inevitable and we are always surprised when a colleague dies of heart disease. We are fairly complacent about the 8000 deaths on the road but are alarmed because one old man is mugged in the East End or one little girl is sexually assaulted: yet the deaths from heart disease in young adults are six times greater than road accidents, and few are concerned. It would also seem that more money is spent on techniques to improve dental and heart surgery than on prevention. Ten years ago there were only two laboratories working on obesity in Britain: now there are about four. Yet at any one time $13 \%$ of the population are trying to lose weight, and in any one year $25 \%$ try. Of course, they don't succeed, and the prevalence rate is increasing, at least in children. The sheer numbers of people in Britain alone who attempt the impossible makes the mind boggle. As taxpayers it 
is not unreasonable that they are given some research resources for their problem. And if it reduces their mortality rate the government might even make a profit on the deal. The mind also boggles at the number of toothless people in Britain. The cost of maintaining a vast army of dentists to deal with the results of a controllable disease is considerable. But one can at least live without teeth, which is more than can be said about hearts. The high cost of intensive care cardiac units might, however, be balanced against the advantages of losing, by default, unproductive middle-aged men. I am sure it is possible to make an economic analysis of these three diseases of affluence but I have left that to others. Suffice it to say that there is plenty to occupy nutritionists for many years to come.

\section{REFERENCES}

Bengoa, J. M. \& Donoso, G. (1974). P. A. G. Bull. 4, 24.

Boyd Orr, J. (1950). Scient. Am. 183 , 11.

Department of Health and Social Security (1969). Rep. publ. Hlth med. Subj. No. I 20 London, HMSO.

Durnin, J. V. G. A. (1979). Bibl. Nutr. Dieta. 27, I.

Durnin, J. V. G. A., Edholm, O. G., Miller, D. S. \& Waterlow, J. C. (1973). Nature, Lond. $242,418$.

Elwood, P. C. (1970). Proc. R. Soc. Med. 63, 1230.

Food and Agricultural Organization (1975). Food and Nutrition. 1, 7.

Food and Agricultural Organization (1977). Food and Nutrition Series, No. 10.

Kelly, F. C. \& Snedden, W. W. (1960). Monograph Ser. WHO No. 44, 27.

Layrisse, M., Roche, M. \& Baker, S. J. (1976). Monograph Ser. WHO No. 62, 55.

Lörstad, M. H. (1974). FAO Newsletter, 12, I.

Matovinovic, J., Child, M. A., Nichaman, M. Z. \& Trowbridge, F. L. (1974). PAHO Scientific Pubn. No. 292, 67. Washington: WHO.

Miller, D. S. (1969). New Scient. Oct. 16, 116.

Miller, D. S. (1976). Proc. R. Soc. B, 194, 23.

Miller, D. S. (1978). In Nutrition, Physical Fitness and Health. [J. Parizkova and V. A. Rogozkin, editors]. Baltimore: University Park Press.

Miller, D. S. \& Parsonage, S. (1975). Lancet i, 773.

Morgan, J., Mumford, P. M., Evans, E. \& Wells, J. (1976). Proc. Nutr. Soc. 35, 74 A.

Schaefer, A. E. (1974). PAHO Scientific Pubn. No. 292, 242. Washington: WHO.

Shapiro, S. (1976). Wld Hlth Stat. Rep. 29, 96.

Schrire, V. (1971). S. Afr. med. $\mathcal{~} .45,634$.

Sood, S. K., Banerji, L. \& Ramalingaswami, V. (Ig68). Symposia. Swedish Nutn. Foundn. VI, Uppsala: Almquist \& Wiksells.

Stones, H. H. (1957). Oral \& Dental Diseases. Edinburgh: Livingstone.

World Health Organization (1972). Tech. Rep. Ser. Wld Hlth Org. No. 503.

World Health Organization (1973). Tech. Rep. Ser. Wld Hlth Org. No. 522.

World Health Organization (1978). WHO Chron. 32, 299. 